\title{
NLRX1 Enhances Glutamate Uptake and Inhibits Glutamate Release by Astrocytes
}

\author{
Shaimaa Mahmoud ${ }^{1}$, Marjan Gharagozloo ${ }^{1}$, Camille Simard ${ }^{1}$, Abdelaziz Amrani ${ }^{2}$ and \\ Denis Gris 1 ,*(D) \\ 1 Program of Immunology, Department of Pharmacology-Physiology, Faculty of Medicine and Health Sciences, \\ University of Sherbrooke, Sherbrooke, QC J1H 5N4, Canada; Shaimaa.Mahmoud@usherbooke.ca (S.M.); \\ Marjan.Gharagozloo@usherbrooke.ca (M.G.); Camille.Simard@usherbrooke.ca (C.S.) \\ 2 Program of Immunology, Department of Pediatrics, CR-CHUS, Faculty of Medicine and Health Sciences, \\ University of Sherbrooke, Sherbrooke, QC J1H 5N4, Canada; Abdelaziz.Amrani@usherbrooke.ca \\ * Correspondence: Denis.Gris@usherbrooke.ca; Tel.: +1-819-346-1110 (ext. 16632)
}

Received: 10 April 2019; Accepted: 28 April 2019; Published: 30 April 2019

check for updates

\begin{abstract}
Uptake of glutamate from the extracellular space and glutamate release to neurons are two major processes conducted by astrocytes in the central nervous system (CNS) that protect against glutamate excitotoxicity and strengthen neuronal firing, respectively. During inflammatory conditions in the CNS, astrocytes may lose one or both of these functions, resulting in accumulation of the extracellular glutamate, which eventually leads to excitotoxic neuronal death, which in turn worsens the CNS inflammation. NLRX1 is an innate immune NOD-like receptor that inhibits the major inflammatory pathways. It is localized in the mitochondria and was shown to inhibit cell death, enhance ATP production, and dampen oxidative stress. In the current work, using primary murine astrocyte cultures from WT and Nlr $x 1^{--}$mice, we demonstrate that NLRX1 potentiates astrocytic glutamate uptake by enhancing mitochondrial functions and the functional activity of glutamate transporters. Also, we report that NLRX1 inhibits glutamate release from astrocytes by repressing $\mathrm{Ca}^{2+}$-mediated glutamate exocytosis. Our study, for the first time, identified NLRX1 as a potential regulator of glutamate homeostasis in the CNS.
\end{abstract}

Keywords: NLRX1; astrocytes; CNS; glutamate uptake; glutamate release; excitotoxicity

\section{Introduction}

Astrocytes are the most numerous glial cell type in the central nervous system (CNS). They perform many pivotal functions associated with neuronal support and maintenance of the CNS homeostasis [1]. One of these crucial functions is to uptake excess synaptically-released glutamate (the major excitatory neurotransmitter in the CNS) [2,3] from the extracellular space, metabolize it, and send it back to neurons $[4,5]$. This glutamate uptake is mediated primarily by the excitatory amino acid transporters 1 and 2 (EAAT1 and EAAT2), expressed by astrocytes (known in mice as glutamate-aspartate transporter (GLAST) and glutamate transporter-1 (GLT-1), respectively) [6-11]. In astrocytes, under physiological conditions, the uptake of glutamate against its concentration gradient relies on glutamate transporters and $\mathrm{Na}^{+} / \mathrm{K}^{+}$ATPase that consumes high levels of intracellular adenosine triphosphate (ATP) [12,13]. Many factors in the CNS influence the expression, trafficking, and functional activity of glutamate transporters in astrocytes, including hormones, growth factors, inflammatory mediators, and oxidative stress [14-16].

Recent studies suggested that, along with glutamate uptake, astrocytes release glutamate, which helps synchronize and intensify firing of the surrounding neurons $[4,17,18]$. Astrocytic glutamate release is mediated mostly by $\mathrm{Ca}^{2+}$-dependent exocytosis [19]. In astrocytes, part of the sequestrated 
glutamate is transferred into small intracellular vesicles $[20,21]$ by activation of the vesicular glutamate transporters 1 and 2 (VGLUT1 and VGLUT2), derived by the proton gradient generated by the vacuolar $\left(\mathrm{H}^{+}\right)$ATPase (V-ATPase) [22-24]. Astrocytes also express a $\mathrm{Ca}^{2+}$ sensor (synaptotagmin 4, 7, or 11) [25-27] and vesicular fusion proteins (vesicle-associated membrane protein 2 and 3 (VAMP2 and VAMP3)) $[20,28]$. In response to intracellular $\mathrm{Ca}^{2+}$ elevation, caused by $\mathrm{Ca}^{2+}$ release from the endoplasmic reticulum (ER), vesicular fusion proteins (VAMP2 and VAMP3) fuse with the astrocyte cell membrane fusion proteins (syntaxin and soluble N-ethylmaleimide-sensitive factor attachment protein 23 (SNAP23)) [29-31], resulting in glutamate release from the vesicles into the extracellular space.

In the context of CNS pathologies, astrocytes respond to inflammation by losing some of their vital functions or acquiring some deleterious effects that aggravate inflammatory conditions in the CNS and delay the processes of recovery [1]. Previous studies showed that neuropathological conditions in the CNS, such as brain trauma, infection by human immunodeficiency virus (HIV), multiples sclerosis (MS), amyotrophic lateral sclerosis (ALS), Alzheimer's disease (AD), and Parkinson's disease (PD) are associated with accumulation of glutamate in the extracellular space, caused by reduced glutamate uptake and/or increased glutamate release by astrocytes [32-37]. Excess extracellular glutamate induces hyperstimulation of glutamate receptors in neurons and eventually leads to neuronal death, in a process known as "glutamate excitotoxicity" [38]. The excess of extracellular glutamate and subsequent neuronal death, in turn, enhance the inflammatory response and worsen the pathological conditions in the CNS [38].

NOD-like receptors (NLRs) are cytosolic innate immune molecules that can exert either positive or negative effects on inflammation in the CNS [39]. NLRX1 is a recently discovered anti-inflammatory NLR that inhibits nuclear factor- $\mathrm{kB}$ (NF-kB) and RIG-1-MAVs signaling pathways, thus inhibiting antimicrobial immune responses [40-44] and sterile inflammations [45]. Since the introduction of Nlr $x 1^{-1}$ mice, many studies implicated NLRX1 in the development of various pathologies. For example, $\mathrm{Nlr}_{\mathrm{N}} \mathrm{I}^{-\mathrm{r}}$ mice show excessive inflammatory response following Influenza virus infection and LPS treatment [41]. Also, Nlrx $1^{-1-}$ mice show exacerbated severity of inflammatory bowel disease (IBD) [46] and increased incidence of colitis-associated colonic cancer [45]. In the CNS, lack of Nlrx1 in mice is associated with an excessive inflammation following CNS trauma [47], earlier onset, and a more aggressive course of the experimental autoimmune encephalomyelitis (EAE), a mouse model of MS [48]. Moreover, using a neuroblastoma cell line, NLRX1 was shown to inhibit neuronal death and redirect rotenone-treated neurons towards apoptosis instead of necrosis [49]. Unlike other NLRs, NLRX1 is located at the mitochondria. It enhances various mitochondrial functions and activities such as ATP production and respiration while inhibiting oxidative stress and apoptosis [44,49-54].

In the current study, we investigated the role of NLRX1 in glutamate uptake and release by primary murine astrocytes, and the potential mechanisms by which NLRX1 mediates its effects.

\section{Materials and Methods}

\subsection{Mice}

All mice handling and manipulations were approved by the Institutional Animal Care and Use Committee at the University of Sherbrooke (Protocols \#280-15, 4 April 2017) according to the Canadian Council on Animal Care. All mice were bred on C57/BL6J background. Wild-type (WT) mice were bred in-house in the same conditions as $N l r x 1^{-1}$ mice that were kindly provided by Dr. Jenny P. Y. Ting (Chapel Hill, NC, USA).

\subsection{Primary Mouse Astrocyte Cultures}

Glial cultures were prepared from 1-day-old pups, as previously described [55]. Pups were sacrificed by decapitation, and brains were harvested and placed in $100 \mathrm{~mm}$ culture plates. Brain tissue was dissociated by a commercial razor blade, followed by triturating in $10 \mathrm{~mL}$ DMEM/F12 medium (Wisent Inc., Montreal, QC, Canada) containing 10\% deactivated fetal bovine serum (dFBS), 
$2 \mathrm{mM}$ L-glutamine, 1\% MEM amino acid, 1\% sodium pyruvate, and 1\% penicillin-streptomycin and amphotericin B (all from Wisent Inc., Montreal, QC, Canada). Dissociated tissue was passed through 70 $\mu \mathrm{m}$ cell strainer to remove tissue debris. Cells were plated in $100 \mathrm{~mm}$ cell culture plates (Corning Inc., Brooklyn, NY, USA) with DMEM/F12 complete medium and incubated in $37^{\circ} \mathrm{C}$ incubator with $5 \% \mathrm{CO}_{2}$. The medium was changed every 2-3 days to wash out cells other than glial cells. After 21 days, glial cultures were resuspended in 10\% dimethyl sulfoxide (DMSO) in dFBS (freezing medium) and were frozen at $-80{ }^{\circ} \mathrm{C}$. One week before the experiments, cells were thawed and reseeded in $100 \mathrm{~mm}$ culture plates, in complete DMEM/F12 medium. Cells were stained with CD11b (eBioscience/Thermofisher scientific, Waltham, Massachusetts, USA \# 12-0112-81) as a marker for microglia and the percentage of CD11b-expressing cells was measured by flow cytometry. In our experiments, we used cultures containing less than $10 \% \mathrm{CD} 11 \mathrm{~b}+$ cells (astrocytes $\geq 90 \%$ ) since additional purification of astrocytes did not affect the glutamate uptake or release.

\subsection{Glutamate Uptake and Release Assay}

The assay was modified from Piao et al. 2015 [56]. 100,000 astrocytes were seeded in each well of a 96-well plate, and washed 2 times with Hank's Balanced Salt Solution (HBSS) containing $\mathrm{Ca}^{2+}$ (Wisent Inc., Montreal, QC, Canada): $1.26 \mathrm{mM} \mathrm{CaCl}_{2}$ (anhydrous), $5.36 \mathrm{mM} \mathrm{KCl}, 0.44 \mathrm{mM} \mathrm{KH}{ }_{2} \mathrm{PO}_{4}$, $0.811 \mathrm{mM} \mathrm{MgSO}_{4}$ (anhydrous), $137 \mathrm{mM} \mathrm{NaCl}, 0.336 \mathrm{mM} \mathrm{Na}_{2} \mathrm{HPO}_{4}$ (anhydrous), $4.166 \mathrm{mM} \mathrm{NaHCO}_{3}$,

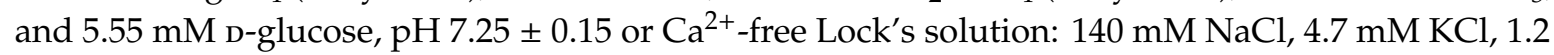
$\mathrm{mM} \mathrm{KH}_{2} \mathrm{PO}_{4}, 1.2 \mathrm{MgSO}_{4}, 11 \mathrm{mM}$ glucose, and $15 \mathrm{mM}$ HEPES-NaOH. For glutamate uptake, cells were incubated with 100 or $200 \mu \mathrm{M}$ glutamate in the $\mathrm{Ca}^{2+}$-containing HBSS for $4 \mathrm{~h}$, while for glutamate release, astrocytes were incubated in $\mathrm{Ca}^{2+}$-containing HBSS or $\mathrm{Ca}^{2+}$-free Lock's solution for $1 \mathrm{~h}$, in the $37^{\circ} \mathrm{C}$ with $5 \% \mathrm{CO}_{2}$ incubator. Then, culture supernatant was collected, and glutamate concentration in the medium was measured using a glutamate colorimetric assay kit (Sigma-Aldrich, Oakville, ON, Canada \# MAK004 or Abcam, Toronto, ON, Canada \#ab83389) according to the manufacturer's instructions. Glutamate uptake by astrocytes was measured by subtracting the amount of glutamate measured in the medium from the amount initially added to the cells. Both glutamate uptake and release by astrocytes were normalized to the amount of protein in the corresponding cells, measured by Bradford assay (Bio-Rad, Montreal, QC, Canada).

\subsection{Quantitative Real-Time PCR ( $q P C R)$}

RNA was extracted from astrocytes using TRIzol reagent (Life Technologies Inc./Thermofisher Scientific, Waltham, MA, USA \# 15596-018) according to the manufacturer's instructions. cDNA was synthesized from RNA, using Oligo(dT) primer (IDT, Coralville, IA, USA), dNTP Mix, M-MuLV Reverse Transcriptase, M-MuLV Reverse Transcriptase Buffer, and RNase inhibitor (all from New England Biolabs, Whitby, ON, Canada), as previously described [55]. qPCR was performed using KiCqStart ${ }^{\circledR}$ SYBR ${ }^{\circledR}$ Green qPCR ReadyMix (Sigma-Aldrich, Oakville, ON, Canada \# KCQS00). The $\Delta \Delta \mathrm{C}_{\mathrm{T}}$ method was used to calculate the relative gene expression to $18 \mathrm{~S}$ as a housekeeping gene [57]. Primer sequences used (IDT, Coralville, IA, USA) are shown in Table 1.

Table 1. Primer sequences used for qPCR.

\begin{tabular}{ll}
\hline \multirow{2}{*}{$18 S$} & $\begin{array}{l}\text { F: 5' CGG CTA CCA CAT CCA AGG AA '3 } \\
\text { R: 5' GCT GGA ATT ACC GCG GCT '3 }\end{array}$ \\
\cline { 2 - 2 } & \multicolumn{1}{c}{ Exocytosis } \\
\hline V-ATPase d2 & F: 5' TTC AGT TGC TAT CCA GGA CTC GGA '3 \\
& R: 5' GCA TGT CAT GTA GGT GAG AAA TGT GCT CA '3 \\
\hline \multirow{2}{*}{ VGLUT1 } & F: 5' GGT GGA GGG GGT CAC ATA C '3 \\
& R: 5' AGA TCC CGA AGC TGC CAT AGA '3 \\
\hline \multirow{2}{*}{ VGLUT2 } & F: 5' CCC TGG AGG TGC CTG AGA A '3 3 \\
\hline
\end{tabular}


Table 1. Cont.

\begin{tabular}{ll}
\hline \multirow{2}{*}{ Synaptotagmin 11 } & F: 5' GAC ACT TGC CGA AGA TGG ATA TC '3 \\
& R: 5' TGC GTT TTC TGC CGT AGT AGA '3 \\
\hline \multirow{2}{*}{ VAMP2 } & F: 5' CAC AAT CTG GTT CTT TGA GGA G '3 \\
& R: 5' AGA GAC TTC AGG CAG GAA TTA G '3 \\
\hline \multirow{2}{*}{ VAMP3 } & F: 5' CTC ACC AAG GCA TCA GTC TG '3 \\
& R: 5' ATT CTA AGA GCA CCA GGC ATC '3 \\
\hline \multirow{2}{*}{ Syntaxin 1a } & F: 5' TCC AAG CTA AAG AGC ATT GAG C '3 \\
& R: 5' GGC GTT GTA CTC GGA CAT GA '3 \\
\hline \multirow{2}{*}{ SNAP23 } & F: 5' AAT CCT GGG TTT AGC CAT TGA GTC '3 \\
& R: 5' TTG GTC CAT GCC TTC TTC TAT GC '3 \\
\hline \multirow{2}{*}{ GLT-1 } & Glutamate transporters \\
\hline \multirow{2}{*}{ GLAST } & F: 5' CGA TGA GCC AAA GCA CCG AA '3 \\
& R: 5' CTG GAG ATG ATA AGA GGG AGG ATG '3 \\
\hline
\end{tabular}

\subsection{Flow Cytometry Staining}

To measure the total protein expression of glutamate transporters, intracellular staining was performed (protocol modified from Gharagozloo et al. 2018 and Schwarz et al. 2013) [58,59]. WT and Nlrx $1^{-/}$astrocytes were washed with phosphate-buffered saline (PBS), fixed, permeabilized, and blocked with 5\% dFBS in washing buffer. Cells were stained with the anti-GLT-1 antibody (Novus Biologicals, Centennial, CO, USA \# NBP1-20136) diluted 1:100 or anti-GLAST antibody (Novus Biologicals, Centennial, CO, USA \# NB100-1869) diluted 1:200 and incubated for 30-40 min. Astrocytes were washed twice and incubated with the secondary anti-rabbit IgG antibody, Alexa Fluor ${ }^{\circledR} 555$ Conjugated (New England Biolabs, Whitby, ON, Canada \#4413) diluted 1:1000, for $20 \mathrm{~min}$. Cells were washed twice after the secondary antibody and resuspended in PBS.

To measure the cell surface expression of the transporters, astrocytes were washed and stained using the same previous procedure, but with no cell fixation or permeabilization.

To detect the activity of reactive oxygen species (ROS), dihydrorhodamine 123 (DHR) was added to the cells to a final concentration of $0.5 \mu \mathrm{g} / \mathrm{mL}$ and incubated for $15 \mathrm{~min}$ at $37^{\circ} \mathrm{C}$, then cells were resuspended in PBS (protocol modified from Gris et al. 2008 and Farrell et al. 2011) [60,61].

Sample acquisition was realized using Beckman Coulter CytoFlex (Beckman Coulter, Brea, CA, USA). Data analysis was performed, and histograms produced using CytExpert 2.3 software (Beckman Coulter, Brea, CA, USA).

\subsection{Measurement of Intracellular ATP}

The assay was performed using the ATP bioluminescent assay kit (Sigma-Aldrich, Oakville, ON, Canada \# FLAA) according to the manufacturer's instructions, modified from Marcaida et al. 1997 [62]. 100,000 astrocytes from WT and Nlr $x 1^{--}$mice were lysed with $400 \mu \mathrm{L}$ of somatic cell ATP-releasing reagent (Sigma-Aldrich, Oakville, ON, Canada \# FLSAR). In a white opaque 96-well plate, $100 \mu \mathrm{L}$ of the ATP reaction mix was added to each well and incubated for $3 \mathrm{~min}$. Samples $(100 \mu \mathrm{L})$ from the ATP standard or the cell lysate were added to the reaction mix and vigorously mixed. Immediately, using a luminometer, the amount of light produced from the reaction was measured, which reflected the amount of ATP in each well.

\subsection{Measurement of Mitochondrial DNA (mtDNA)}

DNA was extracted from astrocytes using TRIzol reagent (Life Technologies Inc./Thermofisher Scientific, Waltham, MA, USA \# 15596-018) according to the manufacturer's instructions. qPCR was performed, as previously described, to compare the relative amount of mtDNA between WT and 
Nlrx $1^{--}$astrocytes [63], using $100 \mathrm{ng}$ of the extracted DNA and KiCqStart ${ }^{\circledR}$ SYBR $^{\circledR}$ Green qPCR ReadyMix (Sigma-Aldrich, Oakville, ON, Canada \# KCQS00). To estimate the amount of mtDNA, the mitochondrial DNA region (D-loop) was amplified, using the two primer sequences: D1 (5'-CCC AAG CAT ATA AGC TAG TAC-3') and D2 (5'-ATA TAA GTC ATA TTT TGG GAA CTA C-3'), with the thermal cycling protocol $95{ }^{\circ} \mathrm{C}$ for $20 \mathrm{~s}, 55^{\circ} \mathrm{C}$ for $20 \mathrm{~s}, 72^{\circ} \mathrm{C}$ for $80 \mathrm{~s}$ for 30 cycles after an initial denaturation. To estimate the amount of nuclear DNA as a reference, the (apo-B) region was amplified, using the two primer sequences: $5^{\prime}$-CGT GGG CTC CAG CAT TCT A-3' and 5'-TCA CCA GTC ATT TCT GCC TTT G-3', with the two-step thermal cycling protocol $95^{\circ} \mathrm{C}$ for $10 \mathrm{~s}$ and $60^{\circ} \mathrm{C}$ for $30 \mathrm{~s}$ for 40 cycles after an initial denaturation at $95^{\circ} \mathrm{C}$ for $1 \mathrm{~min}$. The relative amount of mtDNA to the nuclear DNA was calculated by the $\Delta \Delta \mathrm{C}_{\mathrm{T}}$ method.

\subsection{Statistical Analysis}

All statistical analysis was conducted using GraphPad Prism 8 software (GraphPad, San Diego, CA, USA). Results were expressed as the mean \pm standard error of the mean (SEM). Statistical differences between WT and Nlrx $1^{--}$astrocytes were assessed by Mann-Whitney test. Glutamate uptake and glutamate release using different treatments were assessed by two-way ANOVA followed by Tukey's test. The significance level was set at $p<0.05$.

\section{Results}

\subsection{NLRX1 Inhibits Excess Glutamate Release and Enhances Glutamate Uptake by Astrocytes}

To determine the role of NLRX1 in the glutamate release and uptake by astrocytes, we incubated primary astrocyte cultures from WT and $\mathrm{Nlr}_{x 1^{--}}$mice with or without glutamate in a $\mathrm{Ca}^{2+}$-containing medium. Our data shows that in the cultures incubated with the glutamate-free medium for $4 \mathrm{~h}$ (Figure $1 \mathrm{~A}$ ) or $1 \mathrm{~h}$ (Figure 2A), Nlr $x \mathrm{1}^{--}$astrocytes released significantly higher levels of glutamate compared to WT astrocytes. In the cultures incubated with $100 \mu \mathrm{M}$ glutamate, there was no significant difference in the glutamate uptake between WT and Nlrx $\mathrm{I}^{-/}$astrocytes (Figure 1B). However, when we challenged both cultures with a higher concentration of glutamate $(200 \mu \mathrm{M})$, WT astrocytes significantly enhanced their glutamate uptake, while there was no significant change in the Nlrx $\mathrm{I}^{--}$astrocytes' glutamate uptake (Figure 1B). Therefore, after incubation with $200 \mu \mathrm{M}$ glutamate, WT astrocytes had a significantly higher glutamate uptake (fivefold) than $\mathrm{Nlr} \mathrm{T}^{--}$astrocytes (Figure 1B).

(A)

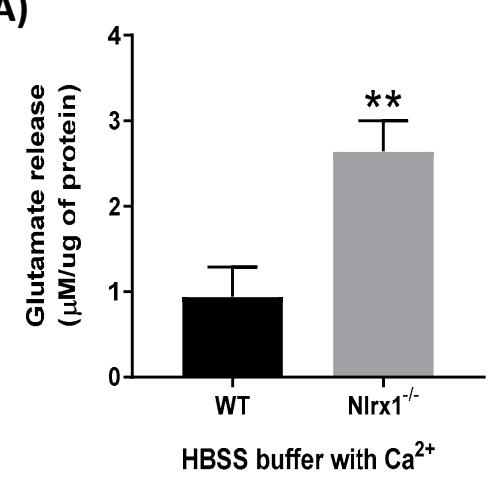

(B)

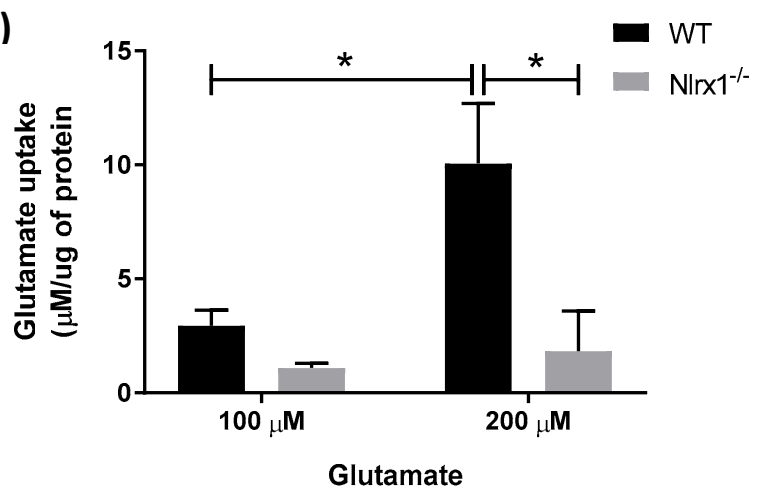

Figure 1. NLRX1 inhibits glutamate release and enhances glutamate uptake by astrocytes. (A) WT and Nlr $x 1^{--}$astrocyte cultures were incubated in glutamate-free, $\mathrm{Ca}^{2+}$-containing HBSS medium. After $4 \mathrm{~h}$, the culture supernatant was collected, and glutamate release in the medium was measured $(n=7)$, ** $p<0.01$ as determined by Mann-Whitney test. (B) For evaluation of glutamate uptake, astrocyte cultures were incubated with 100 or $200 \mu \mathrm{M}$ glutamate in the $\mathrm{Ca}^{2+}$-containing HBSS medium $(n=5)$, ${ }^{*} p<0.05$ as determined by Tukey's test, results are presented as mean \pm SEM. 
(A)

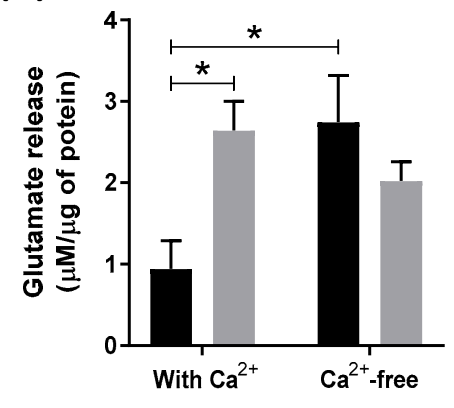

(B)

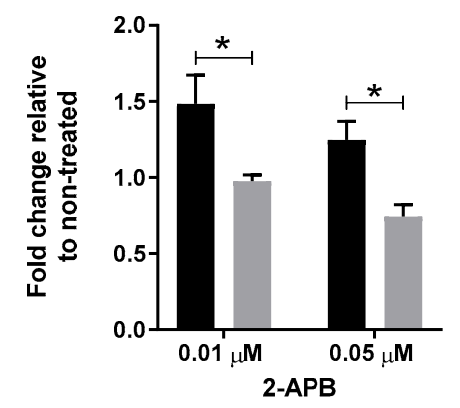

(C)

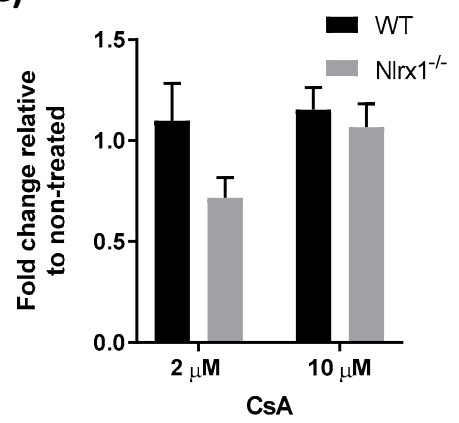

Figure 2. Excess $\mathrm{Ca}^{2+}$ release from the ER mediates glutamate release from $\mathrm{Nlr} x \mathrm{1}^{--}$astrocytes. (A) WT and Nlrx $1^{--}$astrocytes were incubated in a $\mathrm{Ca}^{2+}$-containing HBSS buffer or $\mathrm{Ca}^{2+}$-free Lock's solution for $1 \mathrm{~h}(n=7)$; (B) astrocyte cultures were incubated with 0.01 or $0.05 \mu \mathrm{M}$ of $2-\mathrm{APB}(n=5)$, or $(\mathbf{C})$ with 2 or $10 \mu \mathrm{M}$ of CsA $(n=6)$ in the $\mathrm{Ca}^{2+}$-free Lock's solution for $1 \mathrm{~h}$. The supernatant was collected from all cultures and glutamate in the medium was measured by the glutamate assay kit. ${ }^{*} p<0.05$ as determined by Tukey's test, results are presented as mean \pm SEM.

\subsection{Nlr $x 1^{-1}$ Astrocytes' Excess Glutamate Release Is $\mathrm{Ca}^{2+}$-Dependent}

Given that glutamate release by astrocytes is mediated primarily by the elevation of intracellular $\mathrm{Ca}^{2+}$ levels [18], first, we examined whether the presence of extracellular $\mathrm{Ca}^{2+}$ plays a role in glutamate release from Nlrx $\mathrm{I}^{--}$astrocytes. We incubated WT and $\mathrm{Nlr} \mathrm{1}^{--}$astrocyte cultures in a $\mathrm{Ca}^{2+}$-containing or $\mathrm{Ca}^{2+}$-free medium for $1 \mathrm{~h}$, followed by the measurement of glutamate in the medium. We observed that removal of $\mathrm{Ca}^{2+}$ from the medium resulted in a significant increase in glutamate release from WT astrocytes, while no significant changes in glutamate release were observed in the $\mathrm{Nlr}_{1} \mathrm{1}^{-}$astrocytes (Figure 2A). This suggests that the presence of extracellular $\mathrm{Ca}^{2+}$ does not have a significant effect on glutamate release in $\mathrm{Nlr} x \mathrm{1}^{--}$cultures.

We further assessed whether this glutamate release is mediated by $\mathrm{Ca}^{2+}$ release from the intracellular $\mathrm{Ca}^{2+}$ stores, including ER and mitochondria. We incubated WT and Nlrx $1^{--}$astrocyte cultures with different concentrations of 2-Aminoethyl diphenylborinate (2-APB, an inhibitor of inositol-1,4,5-trisphosphate (IP3) receptors that inhibits $\mathrm{Ca}^{2+}$ release from the ER) [64] or Cyclosporin A (CsA, an inhibitor of mitochondrial $\mathrm{Ca}^{2+}$ release) [65] in the $\mathrm{Ca}^{2+}$-free medium. A significant reduction was detected in the glutamate release from 2-APB-treated $\mathrm{Nlr} \mathrm{I}^{--}$astrocytes at both concentrations, compared to WT (Figure 2B). By contrast, in cultures treated with CsA, no significant change was detected in both genotypes (Figure 2C).

\subsection{Glutamate Release by Nlrx $1^{--}$Astrocytes Is Mediated By Exocytosis}

Since we found that the NLRX1-mediated glutamate release is $\mathrm{Ca}^{2+}$-dependent, we further evaluated whether it is mediated by exocytosis. We measured gene expression of the proteins involved in exocytosis, upstream and downstream of the $\mathrm{Ca}^{2+}$ release from the ER, in WT and Nlr $x 1^{--}$astrocyte cultures. The results demonstrated that the mRNA expression of the astrocytic $\mathrm{Ca}^{2+}$ sensor, synaptotagmin 11, and the vesicular fusion proteins (VAMP2 and VAMP3) was significantly upregulated in $\mathrm{Nlrx}^{-/}$astrocytes relative to WT (Figure 3A), while no significant change was observed in the mRNA expression of the cell membrane fusion proteins (Syntaxin 1a and SNAP23) (Figure 3B) or the proteins upstream of the $\mathrm{Ca}^{2+}$ release (V-ATPase d2, VGLUT1, and VGLUT2) (Figure 3C). 
(A)

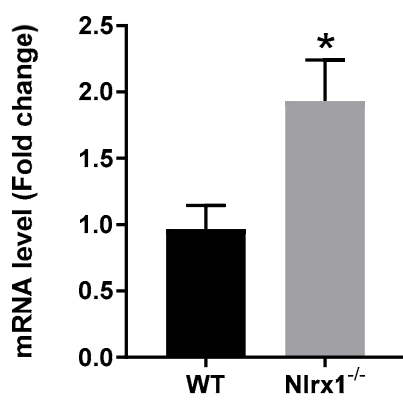

Synaptotagmin 11
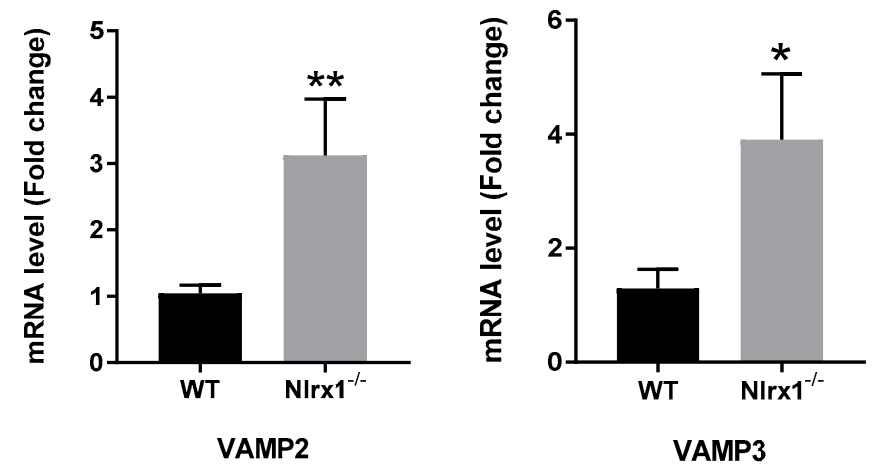

(B)
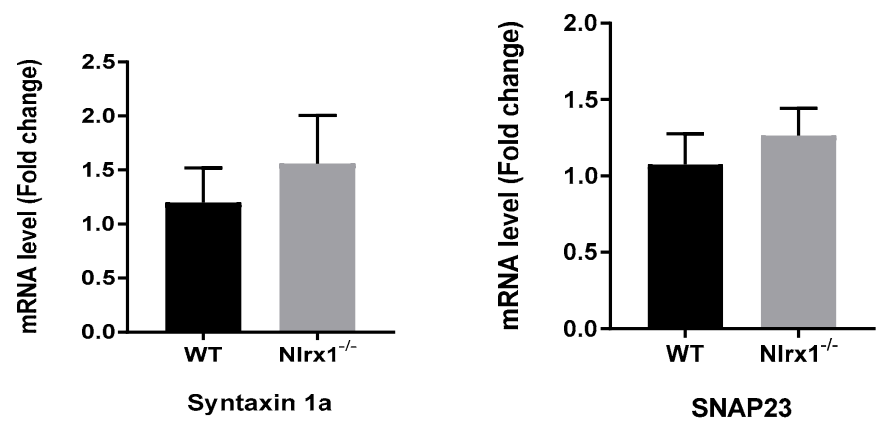

(C)
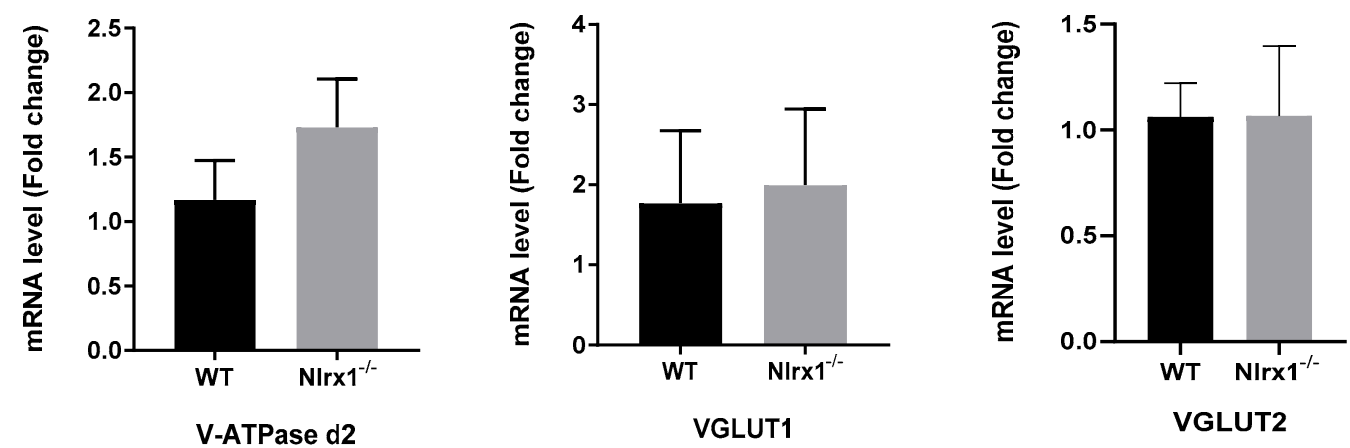

Figure 3. Increased mRNA expression of the proteins of exocytosis in $N l r x 1^{--}$astrocytes. mRNA expression of the proteins of exocytosis in $\mathrm{WT}$ and $\mathrm{Nlr} \times \mathrm{1}^{-/}$astrocytes shows (A) significant upregulation of mRNA expression of the $\mathrm{Ca}^{2+}$ sensor, synaptotagmin 11 , and vesicular fusion proteins, VAMP2 and VAMP3, in Nlr $x 1^{-/-}$astrocytes compared to WT; (B) no significant change in the cell membrane fusion proteins' mRNA expression; and (C) no significant change in the expression of the proteins upstream of $\mathrm{Ca}^{2+}$ release from the ER. ${ }^{* *} p<0.01$ and ${ }^{*} p<0.05$ as determined by Mann-Whitney test $(\mathrm{n} \geq 5)$, results are presented as mean \pm SEM.

\section{4. $m R N A$ and Protein Expression of Glutamate Transporters in Astrocytes}

To further investigate the mechanism by which NLRX1 enhances glutamate uptake, we measured the relative gene expression of the astrocytes' glutamate transporters, GLT-1 and GLAST, in WT and

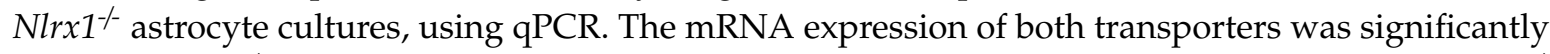

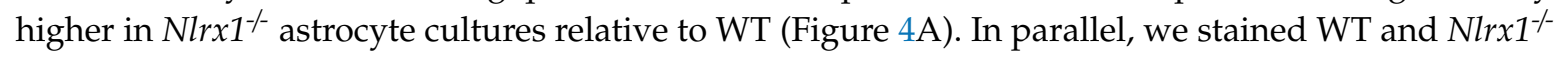
astrocytes with anti-GLT-1 or anti-GLAST antibodies and quantified the total protein expression and the cell surface expression of both transporters by flow cytometry. As shown in Figure 4B,C, no significant change was detected in either GLT-1 or GLAST total protein expression (Figure 4B) or cell surface expression (Figure 4C) between astrocytes of both genotypes. 
(A)

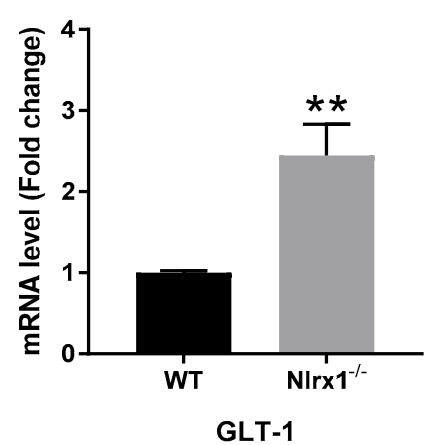

(B)
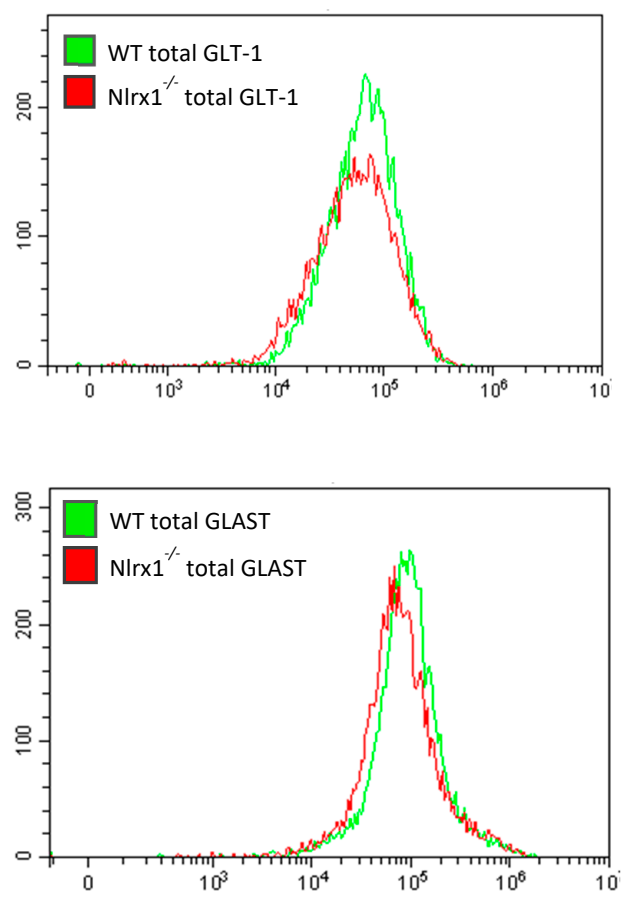

(C)

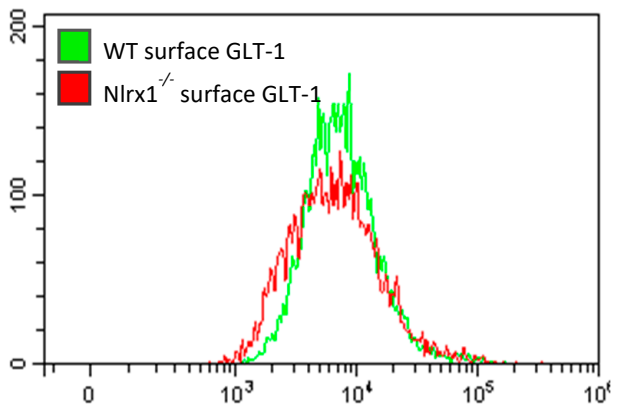

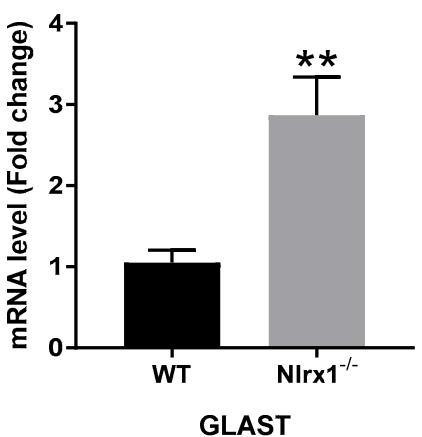
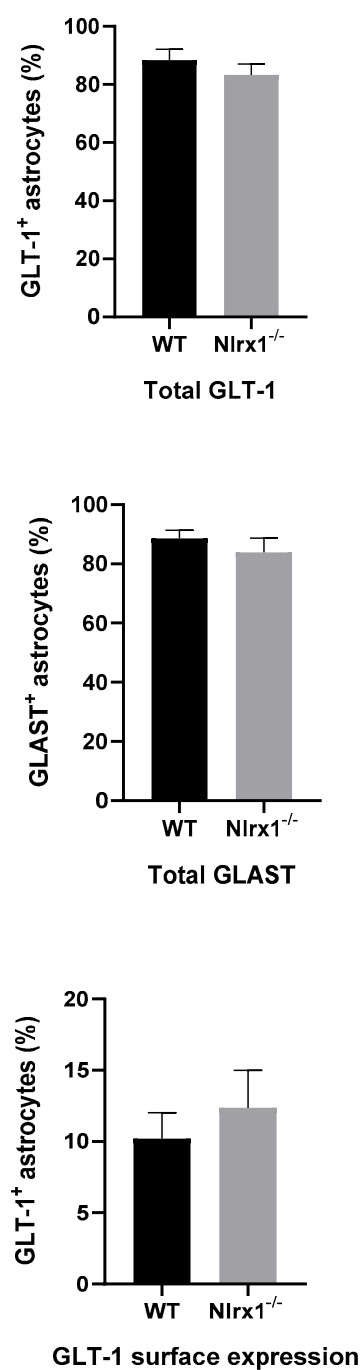

Figure 4. Cont. 

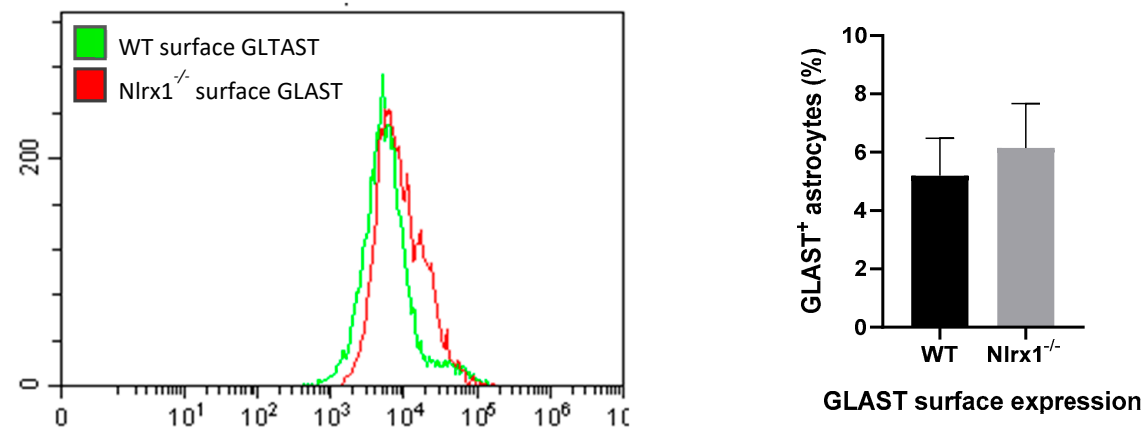

Figure 4. mRNA and protein expression of GLT-1 and GLAST in astrocytes. (A) mRNA expression of GLT-1 and GLAST is significantly upregulated in Nlr $x 1^{--}$astrocytes compared to WT $(n=5)$. ${ }^{* *} p<0.01$ as determined by Mann-Whitney test; (B) the total protein expression of GLT-1 and GLAST proteins in WT and Nlrx $1^{-/}$astrocytes was measured by flow cytometry $(n=5)$; (C) the cell surface expression of both transporters on astrocytes was measured by flow cytometry $(n=7)$. Representative flow cytometric histograms presented on the left side, $p>0.05$ as determined by Mann-Whitney test, results are presented as mean \pm SEM.

\subsection{NLRX1 Enhances Mitochondrial Functions in Astrocytes}

The optimal function of glutamate transporters requires an enormous amount of energy $[12,13]$. Accordingly, we measured levels of intracellular ATP in both WT and Nlrx $1^{-1-}$ astrocytes. We found that $\mathrm{Nlrx}_{1}{ }^{--}$astrocytes have significantly less (20\%) intracellular ATP compared to WT (Figure 5A). Since oxidative stress exerts a negative effect on the functional activity of the transporters [66,67], we measured ROS activity in both WT and Nlrx $1^{--}$astrocytes by flow cytometry. Our results demonstrated that $\mathrm{Nlr} \mathrm{I}^{-\mathrm{t}}$ astrocytes have significantly higher oxidative activity than WT (Figure 5B). Since mitochondria are the major source of intracellular ATP and ROS in the cells, we evaluated the number of mitochondria in WT and $\mathrm{Nlr}_{x 1^{--}}$astrocytes. No significant difference was detected in the amount of mtDNA between WT and Nlrx $1^{--}$astrocytes (Figure 5C).

(A)

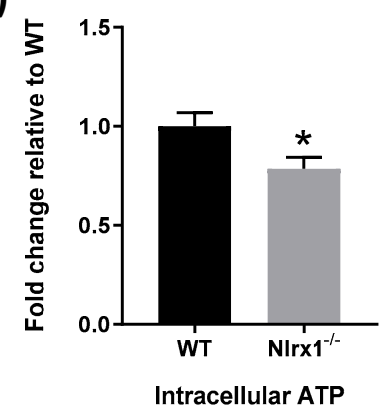

(B)

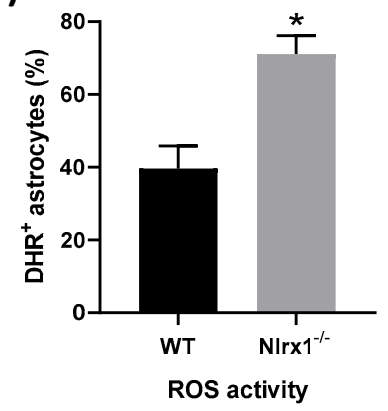

(C)

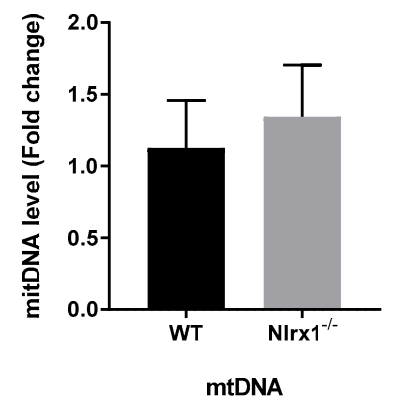

Figure 5. NLRX1 enhances mitochondrial functions in astrocytes. (A) The level of intracellular ATP was measured in WT and Nlrx $1^{--}$astrocytes using an ATP bioluminescent assay kit $(n=5)$; (B) the level of oxidative activity was measured in WT and Nlrx $1^{--}$astrocytes by flow cytometry $(n=4)$; (C) the difference between the amount of mtDNA in WT and $N \operatorname{lr} x 1^{--}$astrocytes was measured by qPCR $(n=3)$. ${ }^{*} p<0.05$ as determined by Mann-Whitney test, results are presented as mean \pm SEM.

\section{Discussion}

In this study, we report that the anti-inflammatory [40-45,47,48] and prosurvival molecule [49], NLRX1, helps maintain glutamate homeostasis in the CNS. Our findings suggest that NLRX1 enhances astroglial glutamate uptake by promoting the functional activity of glutamate transporters, and inhibits glutamate release from astrocytes by suppressing $\mathrm{Ca}^{2+}$-mediated glutamate exocytosis. To our knowledge, this is the first time that one protein has been shown to be implicated in both processes that regulate glutamate homeostasis. 
Given that GLT-1 and GLAST are responsible for the uptake of more than $90 \%$ of the extracellular glutamate in the CNS $[68,69]$, we measured the mRNA and protein expression of these glutamate transporters in astrocytes from WT and $\mathrm{Nlrx}_{1}{ }^{--}$mice. Unexpectedly, the mRNA expression of both transporters was significantly higher in $\mathrm{Nlr} \mathrm{1}^{--}$astrocytes than WT. However, when we measured the total protein expression, as well as the cell surface expression of both transporters, we did not see any significant difference between astrocytes of both genotypes. These findings suggest that the enhanced glutamate uptake in WT astrocytes cannot be attributed to changes in the transcription or translation of the glutamate transporters. In line with our findings, Conrad and Stoffel reported that the direct phosphorylation of GLAST protein by protein kinase C (PKC) reduces its glutamate uptake activity, while immunofluorescence does not show any effect on its protein expression [70]. Another study revealed that arachidonic acid (AA) downregulates glutamate uptake by EAAT-1 by decreasing its affinity to glutamate and the maximal transport rate approximately $30 \%$ with no effect on the expression of its protein [71]. In a third study, Trotti et al. reported that oxidative stress by $\mathrm{H}_{2} \mathrm{O}_{2}$ induces direct oxidation of the sulfhydryl (SH) group of both transporters, which decreases their glutamate uptake with no protein degradation or reduction in their surface expression [72].

Since NLRX1 is localized in the mitochondria, we hypothesized that NLRX1 enhances the glutamate uptake activity of both GLT-1 and GLAST by improving mitochondrial functions in astrocytes. The level of intracellular ATP in astrocytes is one of the crucial factors that determine the functional activity of glutamate transporters [12,13]. Many previous studies reported that ATP depletion, as in cases of brain ischemia, induces glutamate uptake failure caused by loss or reversal of the transporters' function [73,74]. To pay for its own energy consumption, a large portion of glutamate metabolites in astrocytes is consumed in the tricarboxylic acid (TCA) cycle to produce more ATP [75]. Interestingly, we found that $\mathrm{Nlr} \mathrm{I}^{-}$astrocytes contain $20 \%$ less ATP that WT astrocytes, which could either be a cause and/or a result of the reduced glutamate uptake by these cells. Nevertheless, these data, in agreement with the previous studies [50,51], suggest that NLRX1 enhances mitochondrial ATP production.

Moreover, it was reported that the intracellular oxidative stress induced by $\mathrm{H}_{2} \mathrm{O}_{2}$ reduces the functional activity of glutamate transporters $[66,67]$. In this regard, we measured the level of ROS activity in both WT and Nlrx $1^{--}$astrocytes. Our results demonstrated that $N l r x 1^{--}$astrocytes have $50 \%$ more oxidative activity than WT, which could be responsible for the significant deficiency of their glutamate uptake. Furthermore, since there was no difference in the level of mtDNA between WT and Nlr $x 1^{-1}$ astrocytes, we excluded the possibility that NLRX1 increases the number of mitochondria.

Taken together, our results suggest that NLRX1 enhances mitochondrial functions in astrocytes, and thus boosts the functional activity of both GLT-1 and GLAST, rather than their protein expression. This effect of NLRX1 on the transporters is achieved by suppressing oxidative stress and, partially, by maintaining sufficient ATP production.

Recent studies suggest that astrocytes express components necessary for the $\mathrm{Ca}^{2+}$-mediated exocytosis, which is the principal mechanism of astroglial glutamate release under physiological conditions $[4,17-19]$. We evaluated whether the excess glutamate release from $N l r x 1^{--}$astrocytes is $\mathrm{Ca}^{2+}$-dependent. First, to exclude the role of extracellular $\mathrm{Ca}^{2+}$, we incubated astrocytes in $\mathrm{Ca}^{2+}$-free instead of the $\mathrm{Ca}^{2+}$-containing medium. We observed that WT astrocytes significantly upregulated their glutamate release after $\mathrm{Ca}^{2+}$ removal, which agrees with the previously published report by Kostic et al. (2017) [76]. The removal of $\mathrm{Ca}^{2+}$ from the medium stimulates $\mathrm{Ca}^{2+}$ release from the intracellular $\mathrm{Ca}^{2+}$ stores and results in augmentation of glutamate release from astrocytes [76]. However, this does not explain the phenotype in $\mathrm{Nlr}_{\mathrm{N}} \mathrm{I}^{--}$astrocytes, as there was no change between their glutamate release in the $\mathrm{Ca}^{2+}$-containing and the $\mathrm{Ca}^{2+}$-free media, probably because they had already reached their maximum capacity of glutamate release, and $\mathrm{Ca}^{2+}$ removal does not result in any additional effect. In the second step, we evaluated whether this glutamate release occurs in response to $\mathrm{Ca}^{2+}$ release from the intracellular $\mathrm{Ca}^{2+}$ stores. We found that inhibiting $\mathrm{Ca}^{2+}$ release from the mitochondria does not exhibit any significant effect while inhibiting $\mathrm{Ca}^{2+}$ release from the ER reduces the excess 


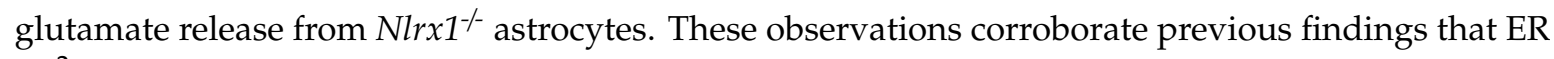
$\mathrm{Ca}^{2+}$ plays an essential role in glutamate release $[4,17]$.

Consequently, $\mathrm{Nlr}_{x 1^{-}}$astrocytes show higher mRNA expression of exocytosis proteins downstream of $\mathrm{Ca}^{2+}$ release from the ER, including the $\mathrm{Ca}^{2+}$ sensor, synaptotagmin 11 , and the vesicular fusion proteins (VAMP2 and VAMP3). In contrast, there is no significant change in the expression of the cell membrane fusion proteins (Syntaxin 1 a and SNAP23), or the proteins preceding $\mathrm{Ca}^{2+}$ release from the ER (V-ATPase d2, VGLUT1, and VGLUT2). Therefore, our results suggest that the excess glutamate release from $\mathrm{Nlrx}^{1-}$ astrocytes is mediated by excess $\mathrm{Ca}^{2+}$ release from the ER, followed by an augmentation in the expression of the molecules of exocytosis as a result of the excess $\mathrm{Ca}^{2+}$ release. Collectively, these data provide evidence that NLRX1 mediates its inhibitory effect on glutamate release from astrocytes mainly by suppressing $\mathrm{Ca}^{2+}$ release from the $\mathrm{ER}$, which consequently suppresses glutamate exocytosis.

The connection between the two mechanisms by which NLRX1 mediates its effects on astroglial glutamate uptake and release is still unclear. Being situated in the mitochondria, it is plausible that NLRX1 modifies mitochondrial functions [44,49-51]. However, the mechanism by which NLRX1 modifies the function of the ER requires more in-depth investigations.

In conclusion, in the current study, we provide evidence that NLRX1 enhances astroglial glutamate uptake and inhibits excess glutamate release from astrocytes, thus maintaining glutamate homeostasis in the CNS (Figure 6-modified from the graphical abstract of our recent publication) [4]. Consequently, NLRX1 represents a potential therapeutic target for the inflammatory and neurodegenerative diseases associated with glutamate excitotoxicity in the CNS.

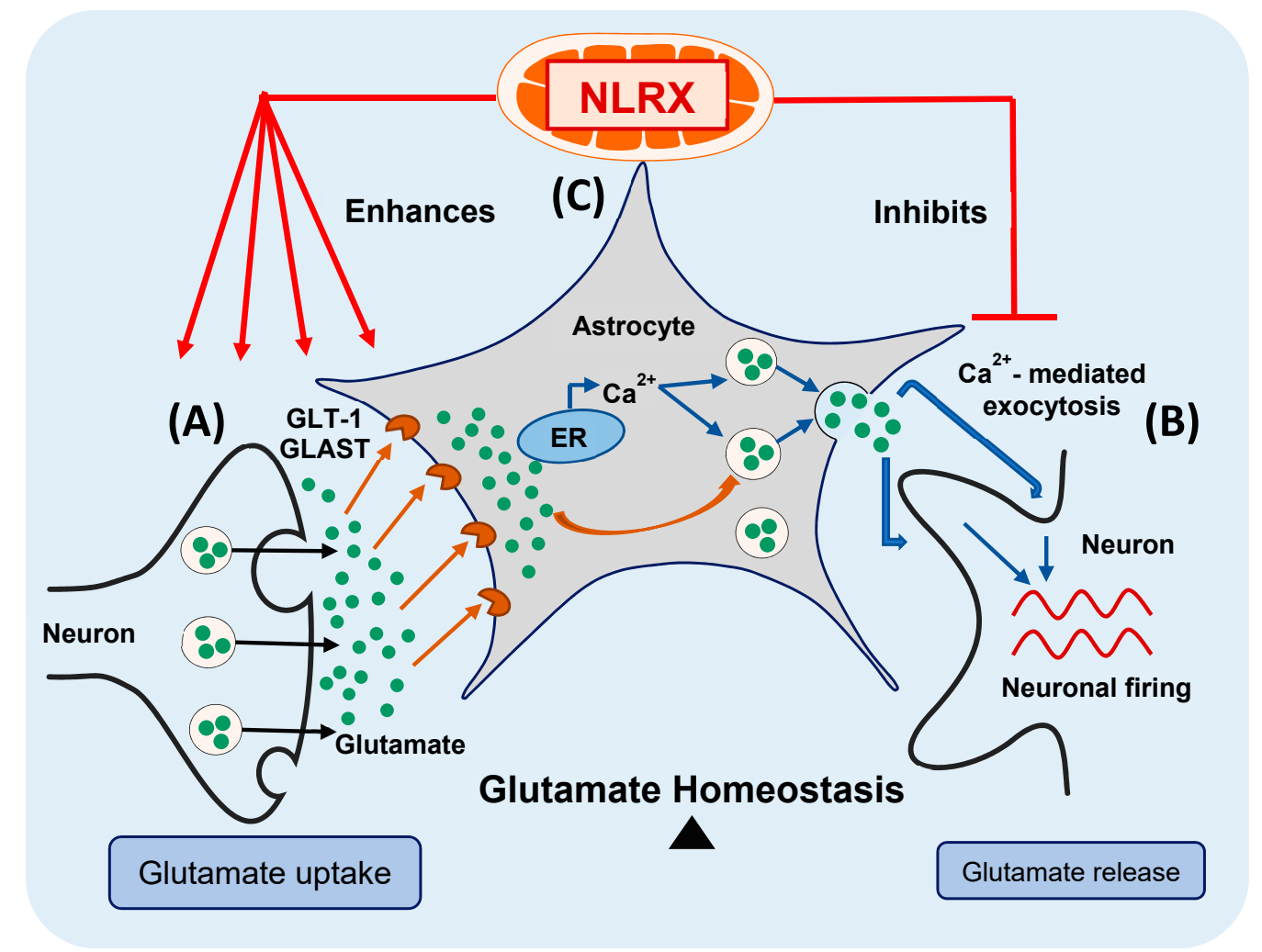

Figure 6. NLRX1 maintains glutamate homeostasis in the CNS. (A) Uptake of the extracellular glutamate by astrocytes is mediated by the glutamate uptake transporters (GLT-1 and GLAST); (B) $\mathrm{Ca}^{2+}$-mediated exocytosis mediates glutamate release from astrocytes, in response to $\mathrm{Ca}^{2+}$ release from the ER. The released glutamate helps to synchronize and reinforce the firing of the surrounding neurons; (C) NLRX1 enhances astroglial glutamate uptake and inhibits its $\mathrm{Ca}^{2+}$-mediated glutamate exocytosis, hence maintaining glutamate homeostasis in the CNS. 
Author Contributions: S.M., A.A., and D.G. designed the study and the experiments. S.M. performed the experiments and the statistical analysis and wrote the manuscript. M.G. and C.S. as second coauthors helped with animal care, genotyping, and culture preparation. M.G. participated in the flow cytometry experiments and their analysis. C.S. performed the ROS experiment by flow cytometry and its analysis. C.S., A.A., and D.G. contributed to the conceptual reading and critical editing of the manuscript. All authors read and approved the manuscript.

Funding: This study was funded by grants from Association de la sclérose en plaques de l'Estrie (ASPE) and Fonds de la recherche en santé du Québec (FRQS) to S.M.

Conflicts of Interest: The authors declare no conflict of interest.

\section{Abbreviations}

\section{CNS}

EAAT1 and EAAT2

GLAST

GLT-1

ATP

VGLUT1 and VGLUT2

V-ATPase

VAMP2 and VAMP3

ER

SNAP23

HIV

MS

ALS

$\mathrm{AD}$

PD

NLRs

NF- $k B$

NLRX1

IBD

EAE

WT

Nlrx $x 1^{--}$

dFBS

DMSO

HBSS

qPCR

PBS

ROS

DHR

mtDNA

SEM

2-APB

IP3

CsA

PKC

AA

$\mathrm{SH}$ group

TCA
Central nervous system

Excitatory amino acid transporters 1 and 2

Glutamate-aspartate transporter

Glutamate transporter-1

Adenosine triphosphate

Vesicular glutamate transporters 1 and 2

Vacuolar (H+) ATPase

Vesicle-associated membrane protein 2 and 3

Endoplasmic reticulum

Soluble N-ethylmaleimide-sensitive factor attachment protein 23

Human immunodeficiency virus

Multiple sclerosis

Amyotrophic lateral sclerosis

Alzheimer's disease

Parkinson's disease

NOD-like receptors

Nuclear factor- $\kappa B$

NOD-like receptor $\mathrm{X} 1$

Inflammatory bowel disease

Experimental autoimmune encephalomyelitis

Wild-type

Nlrx1 knockout

Deactivated fetal bovine serum

Dimethyl sulfoxide

Hank's Balanced Salt Solution

Quantitative real-time PCR

Phosphate-buffered saline

Reactive oxygen species

Dihydrorhodamine 123

Mitochondrial DNA

Standard error of the mean

2-Aminoethyl diphenylborinate

Inositol-1,4,5-trisphosphate

Cyclosporin A

Protein kinase C

Arachidonic acid

Sulfhydryl group

Tricarboxylic acid

\section{References}

1. Sofroniew, M.V.; Vinters, H.V. Astrocytes: Biology and pathology. Acta Neuropathol. 2010, 119, 7-35. [CrossRef] [PubMed] 
2. Curtis, D.; Johnston, G. Amino acid transmitters in the mammalian central nervous system. In Ergebnisse der Physiologie Reviews of Physiology; Springer: Berlin/Heidelberg, Germany, 1974; Volume 69, pp. 97-188. [CrossRef]

3. Fonnum, F. Glutamate: A neurotransmitter in mammalian brain. J. Neurochem. 1984, 42, 1-11. [CrossRef] [PubMed]

4. Mahmoud, S.; Gharagozloo, M.; Simard, C.; Gris, D.; Mahmoud, S.; Gharagozloo, M.; Simard, C.; Gris, D. Astrocytes Maintain Glutamate Homeostasis in the CNS by Controlling the Balance between Glutamate Uptake and Release. Cells 2019, 8, 184. [CrossRef] [PubMed]

5. Anderson, C.M.; Swanson, R.A. Astrocyte glutamate transport: Review of properties, regulation, and physiological functions. Glia 2000, 32, 1-14. [CrossRef]

6. Shashidharan, P.; Plaitakis, A. Cloning and characterization of a glutamate transporter cDNA from human cerebellum. Biochim. Biophys. Acta 1993, 1216, 161-164. [CrossRef]

7. Shashidharan, P.; Wittenberg, I.; Plaitakis, A. Molecular cloning of human brain glutamate/aspartate transporter II. Biochim. Biophys. Acta-Biomembr. 1994, 1191, 393-396. [CrossRef]

8. Storck, T.; Schulte, S.; Hofmann, K.; Stoffel, W. Structure, expression, and functional analysis of a $\mathrm{Na}(+)$-dependent glutamate/aspartate transporter from rat brain. Proc. Natl. Acad. Sci. USA 1992, 89, 10955-10959. [CrossRef]

9. Pines, G.; Danbolt, N.C.; Bjørås, M.; Zhang, Y.; Bendahan, A.; Eide, L.; Koepsell, H.; Storm-Mathisen, J.; Seeberg, E.; Kanner, B.I. Cloning and expression of a rat brain L-glutamate transporter. Nature 1992, 360, 464-467. [CrossRef]

10. Kojima, S.; Nakamura, T.; Nidaira, T.; Nakamura, K.; Ooashi, N.; Ito, E.; Watase, K.; Tanaka, K.; Wada, K.; Kudo, Y.; et al. Optical detection of synaptically induced glutamate transport in hippocampal slices. J. Neurosci. 1999, 19, 2580-2588. [CrossRef] [PubMed]

11. Bergles, D.E.; Jahr, C.E. Glial contribution to glutamate uptake at Schaffer collateral-commissural synapses in the hippocampus. J. Neurosci. 1998, 18, 7709-7716. [CrossRef]

12. Sibson, N.R.; Dhankhar, A.; Mason, G.F.; Rothman, D.L.; Behar, K.L.; Shulman, R.G. Stoichiometric coupling of brain glucose metabolism and glutamatergic neuronal activity. Proc. Natl. Acad. Sci. USA 1998, 95, 316-321. [CrossRef] [PubMed]

13. Pellerin, L.; Magistretti, P.J. Glutamate uptake stimulates $\mathrm{Na}+, \mathrm{K}+-\mathrm{ATPase}$ activity in astrocytes via activation of a distinct subunit highly sensitive to ouabain. J. Neurochem. 1997, 69, 2132-2137. [CrossRef] [PubMed]

14. Gegelashvili, G.; Schousboe, A. High affinity glutamate transporters: Regulation of expression and activity. Mol. Pharmacol. 1997, 52, 6-15. [CrossRef] [PubMed]

15. Chi-Castañeda, D.; Suárez-Pozos, E.; Ortega, A. Regulation of Glutamate Transporter Expression in Glial Cells. Adv. Neurobiol. 2017, 16, 199-224.

16. Sattler, R.; Rothstein, J.D. Regulation and dysregulation of glutamate transporters. Handb. Exp. Pharmacol. 2006, 277-303.

17. Hamilton, N.B.; Attwell, D. Do astrocytes really exocytose neurotransmitters? Nat. Rev. Neurosci. 2010, 11, 227-238. [CrossRef] [PubMed]

18. Parpura, V.; Haydon, P.G. Physiological astrocytic calcium levels stimulate glutamate release to modulate adjacent neurons. Proc. Natl. Acad. Sci. USA 2000, 97, 8629-8634. [CrossRef]

19. Malarkey, E.B.; Parpura, V. Mechanisms of glutamate release from astrocytes. Neurochem. Int. 2008, 52, 142-154. [CrossRef]

20. Bezzi, P.; Gundersen, V.; Galbete, J.L.; Seifert, G.; Steinhäuser, C.; Pilati, E.; Volterra, A. Astrocytes contain a vesicular compartment that is competent for regulated exocytosis of glutamate. Nat. Neurosci. 2004, 7, 613-620. [CrossRef] [PubMed]

21. Chen, X.; Wang, L.; Zhou, Y.; Zheng, L.-H.; Zhou, Z. “Kiss-and-Run” Glutamate Secretion in Cultured and Freshly Isolated Rat Hippocampal Astrocytes. J. Neurosci. 2005, 25, 9236-9243. [CrossRef]

22. Araque, A.; Li, N.; Doyle, R.T.; Haydon, P.G. SNARE protein-dependent glutamate release from astrocytes. J. Neurosci. 2000, 20, 666-673. [CrossRef]

23. Parpura, V.; Zorec, R. Gliotransmission: Exocytotic release from astrocytes. Brain Res. Rev. 2010, 63, 83-92. [CrossRef]

24. Pasti, L.; Zonta, M.; Pozzan, T.; Vicini, S.; Carmignoto, G. Cytosolic calcium oscillations in astrocytes may regulate exocytotic release of glutamate. J. Neurosci. 2001, 21, 477-484. [CrossRef] 
25. Zhang, Q.; Fukuda, M.; Van Bockstaele, E.; Pascual, O.; Haydon, P.G. Synaptotagmin IV regulates glial glutamate release. Proc. Natl. Acad. Sci. USA 2004, 101, 9441-9446. [CrossRef]

26. Wang, C.-T.; Lu, J.-C.; Bai, J.; Chang, P.Y.; Martin, T.F.J.; Chapman, E.R.; Jackson, M.B. Different domains of synaptotagmin control the choice between kiss-and-run and full fusion. Nature 2003, 424, 943-947. [CrossRef]

27. Sugita, S.; Han, W.; Butz, S.; Liu, X.; Fernández-Chacón, R.; Lao, Y.; Südhof, T.C. Synaptotagmin VII as a plasma membrane $\mathrm{Ca}(2+)$ sensor in exocytosis. Neuron 2001, 30, 459-473. [CrossRef]

28. Montana, V.; Ni, Y.; Sunjara, V.; Hua, X.; Parpura, V. Vesicular Glutamate Transporter-Dependent Glutamate Release from Astrocytes. J. Neurosci. 2004, 24, 2633-2642. [CrossRef]

29. Parpura, V.; Liu, F.; Brethorst, S.; Jeftinija, K.; Jeftinija, S.; Haydon, P.G. Alpha-latrotoxin stimulates glutamate release from cortical astrocytes in cell culture. FEBS Lett. 1995, 360, 266-270.

30. Hepp, R.; Perraut, M.; Chasserot-Golaz, S.; Galli, T.; Aunis, D.; Langley, K.; Grant, N.J. Cultured glial cells express the SNAP-25 analogue SNAP-23. Glia 1999, 27, 181-187. [CrossRef]

31. Jahn, R.; Scheller, R.H. SNAREs-Engines for membrane fusion. Nat. Rev. Mol. Cell Biol. 2006, 7, 631-643. [CrossRef] [PubMed]

32. Van Landeghem, F.K.H.; Weiss, T.; Oehmichen, M.; Deimling, A. Von Decreased Expression of Glutamate Transporters in Astrocytes after Human Traumatic Brain Injury. J. Neurotrauma 2006, 23, 1518-1528. [CrossRef]

33. Vesce, S.; Bezzi, P.; Rossi, D.; Meldolesi, J.; Volterra, A. HIV-1 gp120 glycoprotein affects the astrocyte control of extracellular glutamate by both inhibiting the uptake and stimulating the release of the amino acid. FEBS Lett. 1997, 411, 107-109. [CrossRef]

34. Sheldon, A.L.; Robinson, M.B. The role of glutamate transporters in neurodegenerative diseases and potential opportunities for intervention. Neurochem. Int. 2007, 51, 333-355. [CrossRef]

35. Pitt, D.; Werner, P.; Raine, C.S. Glutamate excitotoxicity in a model of multiple sclerosis. Nat. Med. 2000, 6, 67-70. [CrossRef]

36. Bezzi, P.; Domercq, M.; Brambilla, L.; Galli, R.; Schols, D.; De Clercq, E.; Vescovi, A.; Bagetta, G.; Kollias, G.; Meldolesi, J.; et al. CXCR4-activated astrocyte glutamate release via TNF $\alpha$ : Amplification by microglia triggers neurotoxicity. Nat. Neurosci. 2001, 4, 702-710. [CrossRef]

37. Bezzi, P.; Carmignoto, G.; Pasti, L.; Vesce, S.; Rossi, D.; Rizzini, B.L.; Pozzan, T.; Volterra, A. Prostaglandins stimulate calcium-dependent glutamate release in astrocytes. Nature 1998, 391, 281-285. [CrossRef]

38. Wang, Y.; Qin, Z. Molecular and cellular mechanisms of excitotoxic neuronal death. Apoptosis 2010, 15, 1382-1402. [CrossRef]

39. Gharagozloo, M.; Gris, K.V.; Mahvelati, T.; Amrani, A.; Lukens, J.R.; Gris, D. NLR-Dependent Regulation of Inflammation in Multiple Sclerosis. Front. Immunol. 2018, 8, 2012. [CrossRef]

40. Moore, C.B.; Bergstralh, D.T.; Duncan, J.A.; Lei, Y.; Morrison, T.E.; Zimmermann, A.G.; Accavitti-Loper, M.A.; Madden, V.J.; Sun, L.; Ye, Z.; et al. NLRX1 is a regulator of mitochondrial antiviral immunity. Nature 2008, 451, 573-577. [CrossRef]

41. Allen, I.C.; Moore, C.B.; Schneider, M.; Lei, Y.; Davis, B.K.; Scull, M.A.; Gris, D.; Roney, K.E.; Zimmermann, A.G.; Bowzard, J.B.; et al. NLRX1 protein attenuates inflammatory responses to infection by interfering with the RIG-I-MAVS and TRAF6-NF-kB signaling pathways. Immunity 2011, 34, 854-865. [CrossRef]

42. Huang, J.-H.; Liu, C.-Y.; Wu, S.-Y.; Chen, W.-Y.; Chang, T.-H.; Kan, H.-W.; Hsieh, S.-T.; Ting, J.P.-Y.; $\mathrm{Wu}-\mathrm{Hsieh}, \mathrm{B} . \mathrm{A}$. NLRX1 Facilitates Histoplasma capsulatum-Induced LC3-Associated Phagocytosis for Cytokine Production in Macrophages. Front. Immunol. 2018, 9, 2761. [CrossRef]

43. Aikawa, C.; Nakajima, S.; Karimine, M.; Nozawa, T.; Minowa-Nozawa, A.; Toh, H.; Yamada, S.; Nakagawa, I. NLRX1 Negatively Regulates Group A Streptococcus Invasion and Autophagy Induction by Interacting With the Beclin 1-UVRAG Complex. Front. Cell. Infect. Microbiol. 2018, 8, 403. [CrossRef]

44. Ma, D.; Zhao, Y.; She, J.; Zhu, Y.; Zhao, Y.; Liu, L.; Zhang, Y. NLRX1 alleviates lipopolysaccharide-induced apoptosis and inflammation in chondrocytes by suppressing the activation of NF- $\mathrm{B}$ signaling. Int. Immunopharmacol. 2019, 71, 7-13. [CrossRef]

45. Tattoli, I.; Killackey, S.A.; Foerster, E.G.; Molinaro, R.; Maisonneuve, C.; Rahman, M.A.; Winer, S.; Winer, D.A.; Streutker, C.J.; Philpott, D.J.; et al. NLRX1 Acts as an Epithelial-Intrinsic Tumor Suppressor through the Modulation of TNF-Mediated Proliferation. Cell Rep. 2016, 14, 2576-2586. [CrossRef] [PubMed] 
46. Leber, A.; Hontecillas, R.; Tubau-Juni, N.; Zoccoli-Rodriguez, V.; Abedi, V.; Bassaganya-Riera, J. NLRX1 Modulates Immunometabolic Mechanisms Controlling the Host-Gut Microbiota Interactions during Inflammatory Bowel Disease. Front. Immunol. 2018, 9, 363. [CrossRef] [PubMed]

47. Theus, M.H.; Brickler, T.; Meza, A.L.; Coutermarsh-Ott, S.; Hazy, A.; Gris, D.; Allen, I.C. Loss of NLRX1 Exacerbates Neural Tissue Damage and NF-kB Signaling following Brain Injury. J. Immunol. 2017, 199, 3547-3558. [CrossRef]

48. Eitas, T.K.; Chou, W.-C.; Wen, H.; Gris, D.; Robbins, G.R.; Brickey, J.; Oyama, Y.; Ting, J.P.-Y. The Nucleotide-binding Leucine-rich Repeat (NLR) Family Member NLRX1 Mediates Protection against Experimental Autoimmune Encephalomyelitis and Represses Macrophage/Microglia-induced Inflammation. J. Biol. Chem. 2014, 289, 4173-4179. [CrossRef]

49. Imbeault, E.; Mahvelati, T.M.; Braun, R.; Gris, P.; Gris, D. Nlrx1 regulates neuronal cell death. Mol. Brain 2014, 7, 90. [CrossRef]

50. Stokman, G.; Kors, L.; Bakker, P.J.; Rampanelli, E.; Claessen, N.; Teske, G.J.D.; Butter, L.; van Andel, H.; van den Bergh Weerman, M.A.; Larsen, P.W.B.; et al. NLRX1 dampens oxidative stress and apoptosis in tissue injury via control of mitochondrial activity. J. Exp. Med. 2017, 214, 2405-2420. [CrossRef] [PubMed]

51. Singh, K.; Roy, M.; Prajapati, P.; Lipatova, A.; Sripada, L.; Gohel, D.; Singh, A.; Mane, M.; Godbole, M.M.; Chumakov, P.M.; et al. NLRX1 regulates TNF- $\alpha$-induced mitochondria-lysosomal crosstalk to maintain the invasive and metastatic potential of breast cancer cells. Biochim. Biophys. Acta-Mol. Basis Dis. 2019. [CrossRef] [PubMed]

52. Killackey, S.A.; Rahman, M.A.; Soares, F.; Zhang, A.B.; Abdel-Nour, M.; Philpott, D.J.; Girardin, S.E. The mitochondrial Nod-like receptor NLRX1 modifies apoptosis through SARM1. Mol. Cell. Biochem. 2019, 453, 187-196. [CrossRef] [PubMed]

53. Soares, F.; Tattoli, I.; Rahman, M.A.; Robertson, S.J.; Belcheva, A.; Liu, D.; Streutker, C.; Winer, S.; Winer, D.A.; Martin, A.; et al. The mitochondrial protein NLRX1 controls the balance between extrinsic and intrinsic apoptosis. J. Biol. Chem. 2014, 289, 19317-19330. [CrossRef] [PubMed]

54. Jaworska, J.; Coulombe, F.; Downey, J.; Tzelepis, F.; Shalaby, K.; Tattoli, I.; Berube, J.; Rousseau, S.; Martin, J.G.; Girardin, S.E.; et al. NLRX1 prevents mitochondrial induced apoptosis and enhances macrophage antiviral immunity by interacting with influenza virus PB1-F2 protein. Proc. Natl. Acad. Sci. USA 2014, 111, E2110-E2119. [CrossRef] [PubMed]

55. Gharagozloo, M.; Mahvelati, T.M.; Imbeault, E.; Gris, P.; Zerif, E.; Bobbala, D.; Ilangumaran, S.; Amrani, A.; Gris, D. The nod-like receptor, Nlrp12, plays an anti-inflammatory role in experimental autoimmune encephalomyelitis. J. Neuroinflammation 2015, 12, 198. [CrossRef] [PubMed]

56. Piao, C.; Ranaivo, H.R.; Rusie, A.; Wadhwani, N.; Koh, S.; Wainwright, M.S. Thrombin decreases expression of the glutamate transporter GLAST and inhibits glutamate uptake in primary cortical astrocytes via the Rho kinase pathway. Exp. Neurol. 2015, 273, 288-300. [CrossRef] [PubMed]

57. Schmittgen, T.D.; Livak, K.J. Analyzing real-time PCR data by the comparative CT method. Nat. Protoc. 2008, 3, 1101-1108. [CrossRef] [PubMed]

58. Schwarz, J.M.; Smith, S.H.; Bilbo, S.D. FACS analysis of neuronal-glial interactions in the nucleus accumbens following morphine administration. Psychopharmacology 2013, 230, 525-535. [CrossRef]

59. Gharagozloo, M.; Mahmoud, S.; Simard, C.; Mahvelati, T.M.; Amrani, A.; Gris, D. The Dual Immunoregulatory function of Nlrp12 in T Cell-Mediated Immune Response: Lessons from Experimental Autoimmune Encephalomyelitis. Cells 2018, 7, 119. [CrossRef]

60. Gris, D.; Hamilton, E.F.; Weaver, L.C. The systemic inflammatory response after spinal cord injury damages lungs and kidneys. Exp. Neurol. 2008, 211, 259-270. [CrossRef]

61. Farrell, S.M.J.; Groeger, G.; Bhatt, L.; Finnegan, S.; O’Brien, C.J.; Cotter, T.G. bFGF-mediated redox activation of the PI3K/Akt pathway in retinal photoreceptor cells. Eur. J. Neurosci. 2011, 33, 632-641. [CrossRef] [PubMed]

62. Marcaida, G.; Miñana, M.D.; Grisolía, S.; Felipo, V. Determination of intracellular ATP in primary cultures of neurons. Brain Res. Brain Res. Protoc. 1997, 1, 75-78. [CrossRef]

63. Fuke, S.; Kubota-Sakashita, M.; Kasahara, T.; Shigeyoshi, Y.; Kato, T. Regional variation in mitochondrial DNA copy number in mouse brain. Biochim. Biophys. Acta-Bioenerg. 2011, 1807, 270-274. [CrossRef] 
64. Maruyama, T.; Kanaji, T.; Nakade, S.; Kanno, T.; Mikoshiba, K. 2APB, 2-aminoethoxydiphenyl borate, a membrane-penetrable modulator of Ins(1,4,5)P3-induced Ca2+ release. J. Biochem. 1997, 122, 498-505. [CrossRef] [PubMed]

65. Reyes, R.C.; Parpura, V. Mitochondria modulate Ca2+-dependent glutamate release from rat cortical astrocytes. J. Neurosci. 2008, 28, 9682-9691. [CrossRef]

66. Volterra, A.; Trotti, D.; Floridi, S.; Racagni, G. Reactive oxygen species inhibit high-affinity glutamate uptake: Molecular mechanism and neuropathological implications. Ann. N. Y. Acad. Sci. 1994, 738, 153-162. [CrossRef] [PubMed]

67. Sorg, O.; Horn, T.F.; Yu, N.; Gruol, D.L.; Bloom, F.E. Inhibition of astrocyte glutamate uptake by reactive oxygen species: Role of antioxidant enzymes. Mol. Med. 1997, 3, 431-440. [CrossRef] [PubMed]

68. Lehre, K.P.; Danbolt, N.C. The number of glutamate transporter subtype molecules at glutamatergic synapses: Chemical and stereological quantification in young adult rat brain. J. Neurosci. 1998, 18, 8751-8757. [CrossRef] [PubMed]

69. Eulenburg, V.; Gomeza, J. Neurotransmitter transporters expressed in glial cells as regulators of synapse function. Brain Res. Rev. 2010, 63, 103-112. [CrossRef]

70. Conradt, M.; Stoffel, W. Inhibition of the high-affinity brain glutamate transporter GLAST-1 via direct phosphorylation. J. Neurochem. 1997, 68, 1244-1251. [CrossRef]

71. Zerangue, N.; Arriza, J.L.; Amara, S.G.; Kavanaugh, M.P. Differential modulation of human glutamate transporter subtypes by arachidonic acid. J. Biol. Chem. 1995, 270, 6433-6435. [CrossRef]

72. Trotti, D.; Rizzini, B.L.; Rossi, D.; Haugeto, O.; Racagni, G.; Danbolt, N.C.; Volterra, A. Neuronal and glial glutamate transporters possess an SH-based redox regulatory mechanism. Eur. J. Neurosci. 1997, 9, 1236-1243. [CrossRef] [PubMed]

73. Grewer, C.; Gameiro, A.; Zhang, Z.; Tao, Z.; Braams, S.; Rauen, T. Glutamate forward and reverse transport: From molecular mechanism to transporter-mediated release after ischemia. IUBMB Life 2008, 60, 609-619. [CrossRef] [PubMed]

74. Rossi, D.J.; Oshima, T.; Attwell, D. Glutamate release in severe brain ischaemia is mainly by reversed uptake. Nature 2000, 403, 316-321. [CrossRef]

75. McKenna, M.C. Glutamate Pays Its Own Way in Astrocytes. Front. Endocrinol. 2013, 4, 191. [CrossRef]

76. Kostic, M.; Zivkovic, N.; Cvetanovic, A.; Stojanovic, I.; Colic, M. IL-17 signalling in astrocytes promotes glutamate excitotoxicity: Indications for the link between inflammatory and neurodegenerative events in multiple sclerosis. Mult. Scler. Relat. Disord. 2017, 11, 12-17. [CrossRef] 